\title{
Total Diet Study: For a Closer-to-real Estimate of Dietary Exposure to Chemical Substances
}

\author{
Cho-il Kim ${ }^{1}$, Jeeyeon Lee ${ }^{2}$, Sungok Kwon ${ }^{2}$ and Hae-Jung Yoon ${ }^{3}$ \\ ${ }^{1}$ Bureau of Health Industry Promotion, Korea Health Industry Development Institute, Cheongju-si, Korea \\ ${ }^{2}$ Nutrition Management Service Team, Korea Health Industry Development Institute, Cheongju-si, Korea \\ ${ }^{3}$ Food Contaminants Division, Department of Food Safety Evaluation, National Institute of Food and Drug Safety Evaluation, \\ Ministry of Food and Drug Safety, Cheongju-si, Korea
}

(Received August 15, 2015; Revised September 2, 2015; Accepted September 11, 2015)

\begin{abstract}
Recent amendment on the Food Sanitation Act in Korea mandated the Minister of Food \& Drug Safety to secure the scientific basis for management and reevaluation of standards and specifications of foods. Especially because the current food safety control is limited within the scope of 'Farm to Market' covering from production to retail in Korea, safety control at the plane of true 'Farm to Fork' scope is urgently needed and should include 'total diet' of population instead of individual food items. Therefore, 'Total Diet Study (TDS)' which provides 'closer-to-real' estimates of exposure to hazardous materials through analysis on table-ready (cooked) samples of foods would be the solution to more comprehensive food safety management, as suggested by World Health Organization and Food and Agriculture Organization of the United Nations. Although the protection of diets from hazards must be considered as one of the most essential public health functions of any country, we may need to revisit the value of foods which has been too much underrated by the meaningless amount of some hazardous materials in Korea. Considering the primary value of foods lies on sustaining life, growth, development, and health promotion of human being, food safety control should be handled not only by the presence or absence of hazardous materials but also by maximizing the value of foods via balancing with the preservation of beneficial components in foods embracing total diet. In this regard, this article aims to provide an overview on TDS by describing procedures involved except chemical analysis which is beyond our scope. Also, details on the ongoing TDS in Korea are provided as an example. Although TDS itself might not be of keen interest for most readers, it is the main user of the safety reference values resulted from toxicological research in the public health perspective.
\end{abstract}

Key words: Total diet study, Dietary intake, Exposure, Estimate, Mapping

\section{INTRODUCTION}

Although the food safety has been one of the top agenda for the national policy in Korea from long before the President condemned illegal/suboptimal foods for hindering safe society (1), emphasizing the importance of food safety control for population would never be too much. With recent

Correspondence to: Cho-il Kim, Bureau of Health Industry Promotion, Korea Health Industry Development Institute, Osong-eup, Heungdeok-gu, Cheongju-si, Chungcheongbuk-do 28159, Korea E-mail: kimci@khidi.or.kr

This is an Open-Access article distributed under the terms of the Creative Commons Attribution Non-Commercial License (http:// creativecommons.org/licenses/by-nc/3.0) which permits unrestricted non-commercial use, distribution, and reproduction in any medium, provided the original work is properly cited. amendment on the Food Sanitation Act in May 2014, Article 7-4 (Management Plan for standards and specifications of foods) and Article 7-5 (Reevaluation of standards and specifications of foods) were newly inserted and have been enforced form November 2014 (2). In the following ministerial decree, article 5-4 (Establishing management plan) and article 5-5 (Scope of reevaluation) are inserted accordingly to mandate the scientific basis for standards and specifications. There is no doubt that such an improvement in regulation will contribute to the enhancement of food safety in Korea. However, the fact that the current food safety control is mostly limited within the scope of 'Farm to Market' covering from production to retail is rather disturbing. Food safety control at the plane of true 'Farm to Fork' scope should include 'total diet' of population instead of individual food items (3). 
Because chemicals are the building blocks of life and affect many aspects of human metabolism, chemicals can pose health risks to the populations if their presence exceeds their safety thresholds (4). Consequently, the protection of our diets from these hazards must be considered as one of the essential public health functions of any country. This is the main purpose of total diet studies and the reason why World Health Organization (WHO) supports TDS as one of the most cost-effective means for assuring that people are not exposed to unsafe levels of toxic chemicals through foods (4). In this regard, this article aims to provide an overview on TDS for readers while leaving out chemical analysis which will be handled in depth by other articles in the same issue reporting some results from the ongoing TDS in Korea. Although the TDS itself might not be a major topic handled in this journal usually, TDS is the main user of the safety reference values resulted from toxicological research in the public health perspective.

\section{WHAT IS TOTAL DIET STUDY?}

A TDS consists of selecting and purchasing foods which are representative of the diet of the population of interest at the retail level, processing them as for consumption ('tableready' state), often (but not necessarily always) combining the foods into some planned number of food composites, homogenizing them, and analyzing them for chemicals of concern including certain nutrients (5-10). Then, dietary exposures to those chemicals are estimated by combining the concentrations of the chemicals in the prepared (cooked) food samples with the average amounts of the corresponding food ingested by the population. If food consumption data of individuals are available from national scale dietary intake surveys, exposure estimates can be produced for each sex/age group or even more sophisticated subpopulation groups (e.g. income, educational attainment, etc.) also. That is, TDS can be used as a screening tool and for a refined dietary exposure assessment $(11,12)$.

The estimation of the actual dietary exposure to harmful and/or beneficial chemical substances is a prerequisite for risk assessment (6). Although both traditional food monitoring system and the TDS explore the presence and levels of chemical substances in foods and enable exposure assessments, TDS usually results in the most realistic and reliable estimate of chronic dietary exposure to chemicals. TDS provides the information on the levels of interested compounds in the edible portion of the foods at the point of consumption by taking account of possible losses and/or increases during processing and preparation of foods for consumption not only through washing, peeling, and cooking $(6,13,14)$ but also by migration from food packaging during storage, if any.

As the Institute of Medicine and National Research Council (15) suggested, food supply chain is deeply inter- connected with human health, the health of the environment, and social and economic systems. It is also said that 'To ensure that the benefits of a decision outweigh its risks, decision makers must carefully consider the full range of potential effects in the health, environmental, social, and economic domains'. In the same context, the fact that TDS focuses on chemical substances 'across the total diet' of the population differently from other chemical monitoring programs gives enough weight to be the first choice in food safety control. With this, TDS assesses background dietary exposure of population to the regulated and non-regulated chemical substances for public health purposes (16) other than evaluating their levels in the food against regulatory end-points (6).

When conducted over several years repeatedly, TDS provides critical information about the trends of toxic chemicals and other chemicals, such as food additives, in the diet and offers guidance about the need for targeted monitoring or possible intervention programs $(5,16,17)$. A TDS is mainly useful to assess contamination that may be widely distributed across the entire food supply, due to its nature of covering total diet, and that may be present at very low levels, such as heavy metals or dioxin (6). Also, information from TDS often provides direct evidence on the contribution of different food items or food groups to the dietary exposure of chemicals of concern that identification of potentially contaminated foods or food groups is possible. In this case, analysis of composites of individual foods or less aggregated food categories is required (6). Such information can be used to establish priorities in food safety control and assure that limited resources are used for the greatest health benefit (5).

Risk assessments in food safety take account of both toxicological information and estimates of dietary exposure of the population to the chemical substances in order to evaluate benefits and risks for public health $(6,16)$. However, monitoring or surveillance data frequently focus on individual chemical substances in raw food commodities and may not provide a direct link to the dietary exposure (intake) assessment of the population. One example would be the mycotoxins testing in grains (6). Because grains are usually further processed and milled to be used as an ingredient in foods such as breads, cakes or pasta, it is a challenge to estimate the level of mycotoxins in such processed foods on the basis of the contamination in raw commodity. In the absence of analytical data on food as consumed, such as cooked pasta, dietary exposure to mycotoxins may well be over-estimated. That is, exposure estimates are potentially incorrect if based on levels that are detected in raw food commodities following targeted food monitoring or surveillance activities. Actually, the dietary exposure estimates to mycotoxins were reported to be complied fully with European legislation $(18,19)$ or negligible even in the populations with high intake of grains (20). The TDS approach 
provides suitable means for countering the uncertainty associated with such processing and/or preparation of foods we ingest (6).

\section{PROCEDURES INVOLVED IN TOTAL DIET STUDY}

As mentioned earlier, dietary exposure in the TDS can be estimated by multiplying the levels of the chemicals found in food samples by the amount consumed by population for each food and summing them. To make this estimation possible at the last step, there are many other preceding procedures including, but not limited to, deciding chemicals to work on, selecting and purchasing foods representing the diet of the population, preparing them to table-ready state, homogenization, and chemical analysis.
Determination of priority chemicals. Among many chemicals found in our foodstuff, deciding which chemicals to analyze in a TDS is not an easy task. Hence, European Food Safety Authority (EFSA) suggested a series of priority chemicals and some additional consideration was given to this at the $5^{\text {th }}$ International Workshop on Total Diet Studies held in Seoul, Korea in May 2015 (6,21). More detailed discussion on priority chemicals is handled in another article in this Special Issue (22).

Selection of foods representing the diet of the population. The first step in planning and/or conducting TDS would be locating the appropriate information or data source on diet of the population of interest. In general, the nationwide survey on dietary intake is regarded as the best

Table 1. WHO GEMS/Food Consumption Cluster Diets (27)

\begin{tabular}{|c|c|c|c|c|c|}
\hline Cluster & Country & Cluster & Country & Cluster & Country \\
\hline \multirow[t]{17}{*}{ G01 } & Afghanistan & \multirow[t]{36}{*}{ G05 } & Argentina & \multirow[t]{14}{*}{ G10 } & Belarus \\
\hline & Algeria & & Bolivia & & Bulgaria \\
\hline & Azerbaijan & & Brazil & & Canada \\
\hline & Iraq & & Cape Verde & & Croatia \\
\hline & Jordan & & Chile & & Cyprus \\
\hline & Libya & & Colombia & & Estonia \\
\hline & Mauritania & & Costa Rica & & Italy \\
\hline & Mongolia & & Djibouti & & Japan \\
\hline & Morocco & & Dominican Republic & & Latvia \\
\hline & Occupied Palestinian Territory & & Ecuador & & Malta \\
\hline & Pakistan & & El Salvador & & New Zealand \\
\hline & Tunisia & & Guatemala & & Republic of Korea \\
\hline & \multirow{5}{*}{$\begin{array}{l}\text { Turkmenistan } \\
\text { Uzbekistan } \\
\text { Yemen }\end{array}$} & & Guyana & & Russian Federation \\
\hline & & & Honduras & & United States of America \\
\hline & & & India & G11 & $\begin{array}{l}\text { Belgium } \\
\text { Netherland }\end{array}$ \\
\hline & & & Mauritius & \multirow[t]{2}{*}{ G12 } & Belize \\
\hline & & & Mexico & & Dominica \\
\hline \multirow[t]{19}{*}{ G02 } & Albania & & New Caledonia & \multirow[t]{19}{*}{ G13 } & Botswana \\
\hline & Bosnia and Herzegovina & & Nicaragua & & Burkina Faso \\
\hline & Georgia & & Panama & & Central African Republic \\
\hline & Kazakhstan & & Peru & & Chad \\
\hline & Kyrgyzstan & & Seychelles & & Ethiopia PDR \\
\hline & Montenegro & & Suriname & & Gambia \\
\hline & Republic of Moldova & & Tajikistan & & Haiti \\
\hline & Ukraine & & The former Yugoslav Republic of Macedonia & & Kenya \\
\hline & & & Trinidad and Tobago & & Malawi \\
\hline & & & Venezuela, Bolivarian Republic of & & Mali \\
\hline & & & & & Namibia \\
\hline & & & & & Niger \\
\hline & & & & & Nigeria \\
\hline & & & & & Senegal \\
\hline & & & & & Somalia \\
\hline & & & & & Sudan \\
\hline & & & & & Swaziland \\
\hline & & & & & United Republic of Tanzania \\
\hline & & & & & Zimbabwe \\
\hline
\end{tabular}


Table 1. Continued

\begin{tabular}{|c|c|c|c|c|c|}
\hline Cluster & Country & Cluster & Country & Cluster & Country \\
\hline \multirow[t]{2}{*}{ G03 } & $\begin{array}{l}\text { Angola } \\
\text { Benin } \\
\text { Burundi } \\
\text { Cameroon } \\
\text { Congo } \\
\text { Cote d'Ivoire } \\
\text { Democratic Republic of the Congo }\end{array}$ & G06 & $\begin{array}{l}\text { Armenia } \\
\text { Cuba } \\
\text { Egypt } \\
\text { Greece } \\
\text { Iran, Islamic Republic of } \\
\text { Lebanon } \\
\text { Turkey }\end{array}$ & G14 & $\begin{array}{l}\text { Comoros } \\
\text { Fiji Islands } \\
\text { Kiribati } \\
\text { Papua New Guinea } \\
\text { Solomon Islands } \\
\text { Sri Lanka } \\
\text { Vanuatu }\end{array}$ \\
\hline & $\begin{array}{l}\text { Ghana } \\
\text { Guinea } \\
\text { Liberia } \\
\text { Madagascar } \\
\text { Mozambique } \\
\text { Paraguay } \\
\text { Togo } \\
\text { Zambia }\end{array}$ & G07 & $\begin{array}{l}\text { Australia } \\
\text { Bermuda } \\
\text { Finland } \\
\text { France } \\
\text { Iceland } \\
\text { Luxemburg } \\
\text { Norway } \\
\text { Switzerland } \\
\text { United Kingdom } \\
\text { Uruguay }\end{array}$ & G15 & $\begin{array}{l}\text { Czech Republic } \\
\text { Denmark } \\
\text { Hungary } \\
\text { Ireland } \\
\text { Lithuania } \\
\text { Portugal } \\
\text { Romania } \\
\text { Serbia and Montenegro } \\
\text { Slovakia } \\
\text { Slovenia } \\
\text { Sweden }\end{array}$ \\
\hline \multirow[t]{2}{*}{ G04 } & $\begin{array}{l}\text { Antigua and Barbuda } \\
\text { Bahamas } \\
\text { Barbados } \\
\text { Brunei Darussalam }\end{array}$ & G08 & $\begin{array}{l}\text { Austria } \\
\text { Germany } \\
\text { Poland } \\
\text { Spain }\end{array}$ & G16 & $\begin{array}{l}\text { Gabon } \\
\text { Rwanda } \\
\text { Uganda }\end{array}$ \\
\hline & $\begin{array}{l}\text { French Polynesia } \\
\text { Grenada } \\
\text { Israel } \\
\text { Jamaica } \\
\text { Kuwait } \\
\text { Netherland Antilles } \\
\text { Saint Kitts and Nevis } \\
\text { Saint Lucia } \\
\text { Saint Vincent and the Grenadines } \\
\text { Saudi Arabia } \\
\text { United Arab Emirates }\end{array}$ & G09 & $\begin{array}{l}\text { Bangladesh } \\
\text { Cambodia } \\
\text { China } \\
\text { Democratic People's Republic of Korea } \\
\text { Guinea Bissau } \\
\text { Indonesia } \\
\text { Lao People's Democratic Republic } \\
\text { Myanmar } \\
\text { Philippines } \\
\text { Sierra Leone } \\
\text { Thailand } \\
\text { Timor Leste } \\
\text { Viet Nam }\end{array}$ & G17 & $\begin{array}{l}\text { Samoa } \\
\text { Sao Tome and Principe }\end{array}$ \\
\hline
\end{tabular}

source of such information. Although some countries have well-settled national scale nutrition survey in place, there are more countries, mostly developing countries, without any. That is why WHO's Global Environment Monitoring System/Food Contamination Monitoring and Assessment Program (GEMS/Food) has developed the GEMS/Food Consumption Cluster Diets (23) to be used in planning and/ or conducting TDS for those countries with no dietary intake survey in place. GEMS/Food encourages developing countries to undertake total diet studies as a matter of public health importance, while recognizing the significance of total diet studies to standards development and trade as well as environmental risk management (5). The GEMS/Food Consumption Cluster Diets provides an overview of the food consumption worldwide, through 13 dietary patterns covering 183 countries (24). GEMS/Food Regional Diets, the Cluster Diets were developed based on Food Balance
Sheet (FBS) data, which provide estimates of the per capita amount of food available for human consumption during a reference period (typically a year) at the national level. In the development process of the Cluster Diets, 19 marker foods were chosen from 140 foods reported in 183 countries on the basis of a cluster analysis on the 1990 1994 average FBS data. And countries were classified into groups based on the similarity in the consumption levels of these 19 marker foods and their geographical location resulting in 13 clusters, in terms of consumption patterns (25). By the time the Cluster Diets development was completed over 10 years, the 13 cluster diets, including 383 different food items, were derived from the 1997 2001 FBS data for the average consumption value for each country (24).

In 2013, Sy et al. (26) used new approach for the assessment of cluster diets based on a newly available methodology for clustering which was applied to the Supply Utilization 
Account data (SUA) corresponding to the estimated level of per capita consumption collected and analyzed by Food and Agriculture Organization of the United Nations (FAO) (27). SUA data for the period from 2002 to 2007 were processed without adjustment, such as under- or over-reporting corrections, and only missing data or not reported values were taken as zero for computational reasons. All data were represented as a matrix (with real non-negative entries) corresponding to the consumption of 415 primary or semiprocessed food products and 179 country for which a SUA data was available. Finally data were grouped into 62 food groups and the clustering resulted in 17 cluster diets composed of 2 to 30 countries (Table 1). Some discrepancies between these new clusters and former ones (13 clusters) were claimed to be due to more recent data, and to the fact that the new approach is based on another mathematical modeling which does not require any initial identification of food markers (26).

Countries with adequate data on dietary intake of own population from nationwide dietary intake survey or nutrition survey can plan and undertake TDS at more informed level. If the survey produces intake data at individual level with various demographic variables, further analysis on subgroup of population is possible also (28). That is, the comprehensiveness and representativeness of the dietary intake data is the major determining factor on the quality and specificity of TDS results, and more realistic exposure estimates. Although factors involved in the chemical analysis such as sensitivity, reproducibility, precision, accuracy, etc. also matter, the importance of these factors weigh similar between monitoring and TDS.

The next step would be formulating the customized food list for preparation/cooking and chemical analysis while representing the total diet of the population based on the aforementioned data source such as Food Balance Sheets (29), household budget survey data (30), national dietary intake survey data, etc. Generally, this task is performed on the basis of the average intake amount and consumption frequency of commonly consumed foods covering considerable portion (ideally, $90 \%$ or more) of the total food intake of population or subpopulations (31-36). The fullness of the food list depends on the budget and capacity for analysis. Onto this, seasonal and regional variation should be considered in advance that total number of samples to be collected can be projected toward the budget and within time limits allowed. Also, certain foods with probable high level of chemicals/contaminants of concern or emerging chemicals can be included even at very low average intake amounts especially because exposure is subject to both chemical concentration and intake amount. Some foods which are relevant only to specific population subgroups (e.g. infants, children, lactating women, elderly, vegetarians, etc.) may also be included if relevant dietary intake data are available (37). In cases where only background lev- els of chemicals are matter of interest, number of samples for analysis can be reduced to suit to minimal budget by pooling food samples after preparation/cooking according to food groups, seasons, regions, etc. $(10,38)$.

Following the food list formulation, method(s) for food preparation/cooking is determined. It should be based on the usual food consumption habit of the population and the rule of 'more and frequent' is applied also when selecting method(s) by in depth analysis on dietary intake data from national surveys (39). In the cases of US and Korea where very detailed information on dietary habit of population at individual level is available through National Health and Nutrition Examination Survey (NHANES) (40) and Korea National Health and Nutrition Examination Survey (KNHANES) (41) using $24 \mathrm{hr}$ recalls and food frequency questionnaires, more than one method of preparation can be identified for some food items on the food list. For those foods with higher average amount and frequency of consumption, several methods were used in preparation of each food item for chemical analysis in Korean TDS (42), and relative weights are applied to chemical levels in each prepared samples at the step of exposure calculation according to the relative contribution of every cooking method used in total intake of each food $(20,39)$. Since dietary pattern changes over time even within a population (43) and subpopulation groups (44), the food list needs to be revised and regularly updated, ideally before each TDS (45).

Collection of food samples. The third step is collecting food samples on the list while assuring representativeness of nationwide samples. Number of collecting sites is usually determined first within the budget limit and timeframe of the TDS. Selection of collection sites can be based on population size, distance between sites, geographical condition, etc. $(10,46-48)$. Because the aim of a TDS is to generate meaningful exposure estimates which are fit-forpurpose and the best value for the budget available, with the most representative sampling possible, there is always a compromise between the budget, the number of foods on the TDS list, the range of chemicals to be analyzed, the number of samples to be analyzed, the sensitivity of the analytical method used, the time frame available, and the quality of the results (45).

Before sampling begins, volume, weight, or number of units necessary to be purchased per food item has to be determined. Factors that may contribute to this determination are the weights of foods actually needed for the analysis of respective chemicals, whether the analyses are to be done on individual foods or composites of individual foods or on food group composites, and whether excess sample is required to allow for replicate analyses for possible loss/ errors and/or trace-back analysis later (45). In addition, number of preparation methods assigned to each food item should be reflected in estimating the amount of food to pur- 
chase. Because only the edible portion is used in chemical analysis, foods with inedible portion will need more room to compensate for these losses also. Another factor to consider would be that the weight of the food sample changes (decreases in most cases) during the preparation, which needs to be incorporated as a dilution (or concentrating) factor in the final calculation step for exposure estimates (39). Altogether, the amount of food sample to be purchased is easily summed up to become triple or quadruple of that necessary for chemical analysis.

Collected food samples need to be transported to the preparation facility safely and expeditiously for the integrity of samples. For transportation, samples should be packed with an appropriate coolant in suitable containers (39). Upon arrival of collected samples at the preparation facility, they should be checked against the food list and properly stored. Samples requiring refrigeration (perishable ones) or freezing should be stored appropriately in accordance with customary practices in the home and/or in accordance with instructions on the packaging (45). Preparation and/or cooking of perishable food samples need to be completed within days (usually, 48 hours) to ensure the adequate quality of prepared food samples (39).

Preparation of food samples to 'table-ready' state. Preparation of food samples needs to be done systematically to minimize any variation due to preparer, preparation time, heating condition, utensils used, etc. For these reasons, it is necessary to keep clear record of every procedure at every step in detail, preferably with pictures (49). That is, standard operating procedures (SOPs) for preparation including description on sample preparation equipment are essential (45). It is important to be sure that there is no cross contamination of any kind between the samples and careful cleaning and drying of utensils and equipments in between use is necessary. Gloves should be worn for the whole procedure of preparation to avoid the food being prepared coming into contact with hands. Equipments and utensils used in preparation need to be free of chemicals analyzed in the TDS also. Sample containers should be selected carefully in terms of materials and size for the respective analytes and suitable for long-term freezing without leaching $(45,49)$.

Depending on the approaches used in preparing the TDS analytical samples, namely the food group approach or the individual foods approach, steps after the food preparation as normally consumed in the home are determined. In the food group approach $(10,50,51)$, different foods from the same food group are combined to form a new food group or subgroup sample for analysis (e.g. apples and pears to form 'pome fruit group') after preparation (45). By combining food samples using a food group approach, number of composite samples required to represent the total diet can be reduced to cope with the limited budget because the expenses associated with analysis will vary parallel to the number of samples. However, the food group approach has one obvious disadvantage, the dilution effect on the exposure estimates (52). When a food has concentrations of the chemical of interest well above detectable levels, its combination with numerous other foods with no detectable concentrations may result in the composite sample with concentration below the Limit of Detection (LOD). Another disadvantage is that even with an elevated concentration identified from a specific food group sample, it is not possible to determine which food(s) in that food group sample is a major contributor(s). For this reason, samples of the original foods contributing to the food group composite sample should be retained and used in trace-back analysis to find out the individual food samples that actually contributed to the elevated level. Also, it is not possible in this approach to calculate exposure for subpopulations other than the population from which the combination ratio for composites is derived.

In the individual food approach $(8,53,54)$, each food in the TDS food list is analyzed separately after preparation without compositing. Of course sample composite combining samples from different collection sites $(39,55)$, regions (56), or brands, etc. can be made according to the TDS design. In Australia (57), which also used the individual foods approach, different brands were combined to form multiple composites of the individual foods. For the individual foods approach, the major advantage is that it allows much greater flexibility in calculating dietary exposure estimates for subpopulations of different age, gender, socioeconomic groups, etc. provided that the respective consumption data are available as in the cases of US or Korea $(41,42,58,59)$. The disadvantage of this approach is the larger number of samples that need to be analyzed to represent the foods commonly consumed by the population ( $>100 \sim 300$ individual foods compared to perhaps only 20 50 food groups) and, accordingly, cost much more than the food group approach.

Sample storage. Samples prepared for chemical analysis need to be dispatched to the analytical laboratories as soon as possible, preferably. If necessary, it should be stored in a manner that does not compromise the integrity of the sample especially because some analytes (e.g. Vitamin A, carotenoids, and riboflavin) are sensitive to light, temperature, etc. Usually prepared samples are stored in the air-tight containers at $-20^{\circ} \mathrm{C}$ or lower $(60,61)$. Each TDS food sample containers should be adequately labeled in advance for correct analyses including food name, date and method of preparation before they are filled and sent out to the analytical laboratories. Reserve samples are usually retained for at least several months after the TDS results have been reported (45). They may also be stored in several aliquots to avoid repeated thawing and freezing and for longer period 
as a resource for analysis on substances other than those processed in the TDS (62-64) or subsequent related investigations involving food matrices $(65,66)$.

Analysis of chemicals. Although the chemicals processed in TDS are different among countries and time, most of them are covered by priority chemicals suggested by WHO (37) and EFSA (6). With many different groups of chemicals and levels of precision and accuracy required by each TDS, some examples of chemical analysis along with method validation will be handled in a series of subsequent articles in this Special Issue for those hazardous materials produced in the process of cooking and/or industrial processing of food.

Dietary exposure assessment. The last step in a TDS would be the dietary exposure assessment leaving the risk communication for next. The main purpose of this step is to estimate likely levels of exposure to food chemicals for the population and/or population sub-groups from the diet and the associated level of risk to public health and safety $(67,68)$. WHO and FAO have prepared an overview of the various dietary exposure assessments, including recommended methodologies and approaches to interpreting the results for international, regional, national, and local applications (68).

The general equation for dietary exposure is as follows:

$$
\begin{aligned}
& \text { Dietary Exposure }=\Sigma(\text { Food Intake } \\
& \quad \times \text { Chemical Concentration in Food })
\end{aligned}
$$

Although the equation looks quite simple, applying this formula to estimate exposure is rather complicated because of the diversity of food supplies and variations in dietary pattern including cooking/preparation of foods. Estimating exposure for the entire population requires combining food intake data for many individuals on many days and seasons, which are rarely available. This leads to the discussion of statistical procedures estimating usual dietary intakes by combining food intake data from $24 \mathrm{hr}$ recalls and information from specific food frequency (propensity) questionnaire $(69,70)$. However, even with statistical procedures, getting enough information on population's usual diet for longer period is not feasible especially because aforementioned methodology is more suited for nutrient intake. Also, it is not possible to have chemical concentrations in all foods the target population consumes. Hence, mapping of non-TDS foods to TDS foods (57) can be considered for more comprehensive coverage of total diet, which will be discussed under the next subheading. Also statistical modeling can be used with various datasets for chemical concentration and food intake to conduct simulations, which consider the impact of different assumptions and different policy options on the resulting exposure estimates (71).
Dietary exposure estimates are best interpreted by comparison to a toxicological endpoint or nutritional reference value for the food chemical of concern. Typically, a mean dietary exposure will be compared with a chronic (long-term) toxicological reference value, such as the acceptable daily intake, provisional tolerable weekly intake, or Benchmark Dose (71). In the comparison of results with the reference values, the dietary exposure estimates need to be converted to units/kg body weight/day if the health-based guidance value for hazardous materials is in body weight based (units/kg body weight/day). In a deterministic method, the mean dietary exposure is divided by the average body weight for the population group/sub-group of interest. If using a semi-distributional or probabilistic method based on individual dietary intake data, the dietary exposure for each individual in the population group/sub-group is divided by their own body weight and may be compared to the healthbased guidance value or their individual health-based guidance values, if available for different age groups, sexes, etc. Then the mean and low or high percentile dietary exposures for the whole population or sub-population group are derived (67).

In estimating a dietary exposure for a total diet study, it is important to determine the purpose of the estimation and the questions that need to be answered. This will guide the choices of dietary exposure assessment methodology, food chemical concentrations, and food intake data along with the population group and/or sub-groups to examine (67). The accuracy of these dietary exposure estimates depends on the quality of the data used in the calculations, the preparation of which often takes more time than the actual dietary exposure calculations. The dietary exposure assessment methodology used in a TDS will depend on the goals for the study and the data, time and financial resources available (72). While the initial focus of most total diet studies have been on assessing dietary exposures to Radionuclides (16), pesticide residues $(73,74)$, contaminants $(10,64,75)$, and nutrients $(63,65,76)$, total diet studies have also been used for estimating dietary exposure to food additives $(57,76)$. Recently, the hazardous materials produced in the process of industrial food processing and/or cooking and environmental pollutants have been the subject of total diet studies also $(28,39,49,61,77,78)$.

Total diet studies are usually designed to estimate longterm dietary exposures to chemicals through foods. The data from the dietary exposure assessment should be compiled in a way that allows the risk assessment questions to be answered. The information on dietary exposure that may be compiled and reported for total diet studies include followings (67), but not limited to:

- Mean dietary exposures for each population group/subgroup

- High percentile dietary exposures for each population group/sub-group (where individual dietary intake data have 
been used)

- Low percentile dietary exposures for each population group/sub-group (nutrients only, where individual dietary intake data have been used)

- Comparison to the health-based guidance value (e.g. \% health-based guidance value; proportion of population above or below the health-based guidance value when individual dietary intake data have been used)

- Foods or food groups that are major contributors to the estimated dietary exposures

- Summary of food intake data.

Mapping of other foods to representative foods. No matter how many food samples are included in a TDS food list, there is still a possibility of underestimation in the exposure estimates due to non-TDS foods (79). Practically, it is not possible to include every single food that population consumed in a TDS, and even with a list covering more than $90 \%$ of total food intake of the population, there are other foods, usually with small average intake or infrequent consumption, left out counting for $10 \%$ or so. To control for this type of limitation, Australian TDS $(57,67)$ has adopted 'food mapping' to estimate total dietary exposure to chemicals from all foods. In this method, non-TDS foods reported as consumed in the food intake data are matched to the representative foods (TDS foods) based on the similarity using a so-called 'best-fit' approach. This conservative estimation is designed to ensure that the dietary intake assessment does not underestimate the intake of toxic chemicals. Similar approach was applied to re-estimate the exposure to heavy metals using previous TDS results in Korea and the authors reported approximately 50\% increase in exposure estimates (80). In that study, they mapped non-TDS foods (about $80 \%$ of all food items reported in the national dietary intake survey (81)) to TDS foods used in 2009 Korean TDS (75) according to closeness in biological systematics and morphological similarity. Therefore, multiple foods within the same food group were mapped to a single TDS food, in principle. Habitat of plants and aquatic living organisms also was taken into consideration in mapping in order to minimize the possible differences in the heavy metal content that would result from different living and/or cultivating environments (80). In the subsequent total diet studies using mapping method reflecting hydration and raw equivalence factors (82) based on the water content and macronutrient content of foods, the authors found $10 \sim 50 \%$ increase in exposure estimates depending on the chemicals (ubiquitous in foods or not) and the comprehensiveness of the TDS food list $(39,80)$.

Although the introduction of mapping gives higher exposure estimates than without, it enables the estimation of total exposure, nominally and virtually, to a given chemical. Applying this to descriptive dietary intake data of individuals with health data such as body weight at a population level, hence, results in a true distribution of exposure estimates over population. This approach produces different results from the one produced by semi-distributional method using point estimate of chemical concentration and distribution of food intake or the one produced by deterministic method based on the point-estimate of chemical concentration and average food intake for each food analyzed. While the probabilistic method is based on the distributions of food intake and food chemical concentrations with statistical program, it is usually used with chemical concentra-

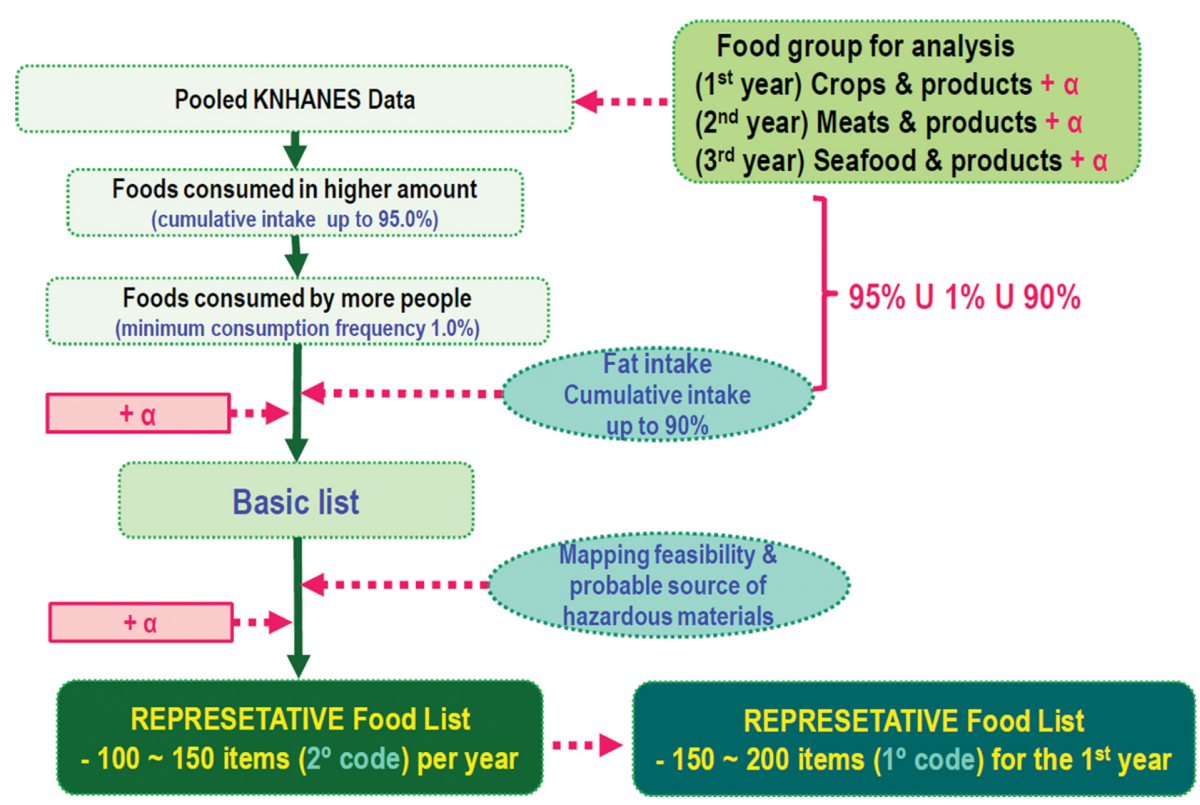

Fig. 1. Flow chart for selecting representative foods for chemical analysis. 
tions from monitoring data because TDS food samples are often composited. Accordingly, the high percentile dietary exposures estimated with mapping are realistic because they are derived from the sum of foods that people actually consumed without any extrapolation, assumption, etc. which often brings about unrealistic and excessive over-estimation (39).

\section{ONGOING TOTAL DIET STUDY IN KOREA}

Following intermittent TDS in Korea over 2 decades, developing a refined plan for TDS customized for Koreans was attempted in 2011 (83). Using other countries' reports and articles related to TDS, data was compiled to build a database of 83,149 records on contaminant levels in food and dietary exposure. It was used as the primary source of information in determining the priority of food contaminants and establishing principles to select representative foods for the Korean TDS. Considering typical dietary practices of Koreans, the mid- to long-term road-map for Korean TDS was also devised with operating scheme.

Based on the aforementioned study, the Ministry of Food and Drug Safety planned and launched a large scale TDS focusing on 23 hazardous materials produced during processing and cooking for 3 year period in 2013. This TDS is conducted by a team of more than 100 researchers from academia, industry and research institutes producing the interim progress reports for the $1^{\text {st }}$ and $2^{\text {nd }}$ year $(49,84)$ and some of the results regarding the analyses are reported in subsequent articles in this Special Issue.

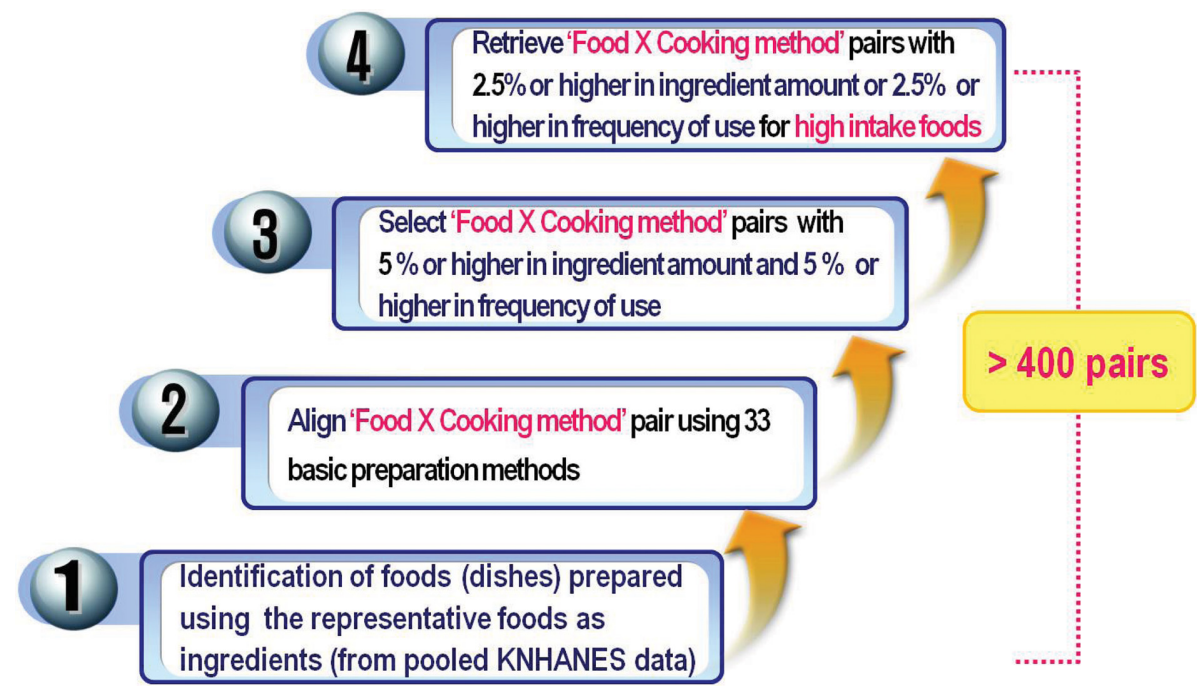

Fig. 2. Steps in selecting preparation methods for food samples each year.

Table 2. Basic methods used in food sample preparation

\begin{tabular}{|c|c|c|c|c|c|}
\hline No. & Preparation & Example & No. & Preparation & Example \\
\hline 1 & Roasted/grilled & Beef & 18 & Stir fried and pan fried & Mushroom (omelet) \\
\hline 2 & As is/raw & Strawberry & 19 & Stir fried and simmered & Beef (spaghetti sauce) \\
\hline 3 & Pan fried & Wheat flour & 20 & Soaked in water & Dried seaweed \\
\hline 4 & Pan fried and boiled & Tofu & 21 & Soaked in water and boiled & Dried seaweed (soup) \\
\hline 5 & Blanched/parboiled & Spinach & 22 & Soaked in water and stir fried & Dried fern/bracken \\
\hline 6 & Blanched and pan fried & Bean sprouts (mung bean pancake) & 23 & Boiled and strained (use solid mass) & Pork \\
\hline 7 & Blanched and steamed & Cabbage (wonton) & 24 & Boiled, strained and baked & Spaghetti (oven) \\
\hline 8 & Blanched and boiled & Bean sprouts (wonton in stew) & 25 & Boiled, strained and boiled & Noodles (stew) \\
\hline 9 & Blanched and stir fried & Perilla leaves & 26 & Boiled, strained and stir fried & Spaghetti \\
\hline 10 & Boiled & Kimchi (stew) & 27 & Boiled, strained and pan fried & Pork (mung bean pancake) \\
\hline 11 & Boiled water added & Powdered infant formula & 28 & Boiled, strained and steamed & Starch noodle (wonton) \\
\hline 12 & Boiled and taken out (use liquid) & Dried anchovy & 29 & Boiled, strained and fried & Starch noodle (wonton) \\
\hline 13 & Steamed (rice) & White rice & 30 & Steamed & Corn \\
\hline 14 & Steamed (rice) and boiled & Rice (rice in soup) & 31 & Steamed and fried & Wonton (fried wonton) \\
\hline 15 & Steamed (rice) and stir fried & Fried rice & 32 & Steamed or baked & Sweet potato \\
\hline 16 & Steamed (rice) and pan fried & Rice (scorched rice) & 33 & Fried & Potato (French fries) \\
\hline 17 & Stir fried & Vegetables & & & \\
\hline
\end{tabular}


Embracing the procedures involved in TDS described above, this study was designed to cover total diet of the Korean population as comprehensive as possible resulting in a representative food list corresponding to more than $98 \%$ of total food intake based on the pooled dietary intake data from KNHANES 2008 through 2011 (85). Foods consumed in higher amount (cumulative intake up to 95\%) and by more people (consumption frequency of $1.0 \%$ or higher) were chosen with some addition to cover $90 \%$ of cumulative fat intake and consider mapping feasibility, probable source of target hazardous materials, etc. (Fig. 1). This resulted in 358 food items at the $2^{\circ}$ food code level, which was translated into more than 500 food items at the $1^{\circ}$ food code level.

Food groups were assigned evenly over 3 years for collection, preparation and analysis, while the preparation methods for each food items were selected by the rule of 'more and frequent'. Based on over 15,000 recipes for which the aforementioned 358 food items were used as ingredients in preparation, utilizing the raw data on dietary intake from 2008 2011 KNHANES, representative cooking method(s) were selected for each food item on the list by choosing method(s) used in cooking $5 \%$ or more of that food intake amount, or with frequency of $5 \%$ or higher. Onto this, 'food $\times$ cooking method' pairs with $2.5 \%$ or higher ingredient amount, or $2.5 \%$ or higher frequency of use for food items of high average intakes were included additionally. As a result, about 400 'food $\times$ cooking method' pairs were extracted for each year. Flow of selection process for sample preparation method is shown below (Fig. 2) and basic preparation methods with corresponding example foods are given in Table 2.

For food sampling, 9 metropolitan cities with population size larger than 1 million people were chosen based on the resident registry (86) and number of markets were assigned by population size. In each city, district(s) was selected based on the number of residents and mega-markets were singled out by yearly sale records (Fig. 3). Total of 18 mega-markets in 9 cities were used as collection sites and sample purchase was repeated every week over 7-8 months each year. Collected samples were packed in a cooler and transported to the central preparation facility in the same day of purchase (Fig. 4). Perishable food samples stored in a refrigerator were prepared within 2 3 days of purchase. At each step of preparation, weight of sample was recorded to derive corresponding dilution (or concentration) factor to be used for later calculation. Once prepared, samples were homogenized, bottled in appropriate containers, frozen at $-20^{\circ} \mathrm{C}$, and dispatched to 11 laboratories for chemical analysis.

Based on the chemical concentration in each sample of

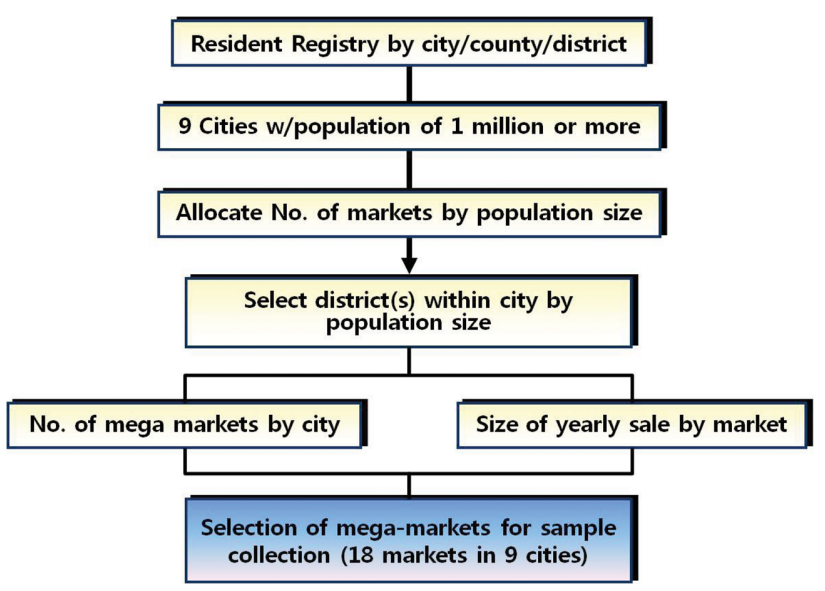

Fig. 3. Flow chart for sampling site selection.

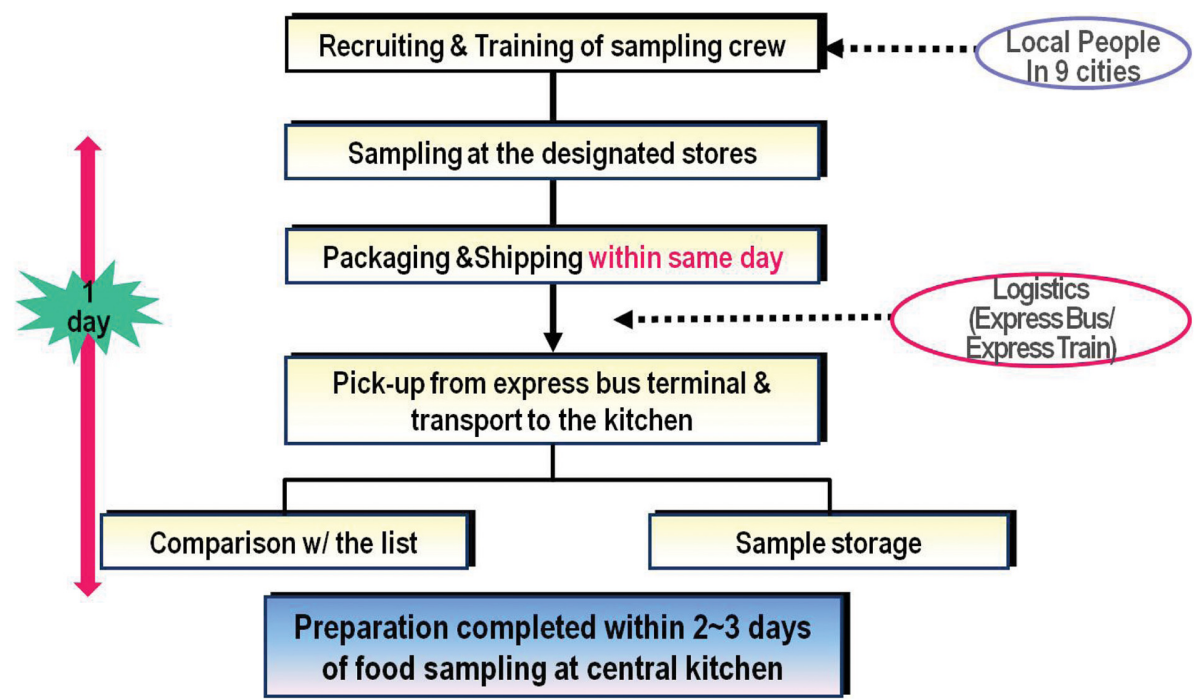

Fig. 4. Time frame of food sampling and preparation. 
'food $\times$ cooking method', exploratory exposure was estimated without mapping for each analytes at individual level and reported in the interim progress reports $(49,84)$. At the end of the $3^{\text {rd }}$ year, total dietary exposure of the Korean population will be estimated using mapping with all TDS foods analyzed and high percentile dietary exposure will be determined based on the distribution of individual exposure level.

\section{CONCLUSION}

As WHO and FAO suggested, TDS can be used in many aspects as a screening tool to identify foods or food groups for detailed monitoring or surveillance, as a risk management tool to develop priorities for possible public intervention, as an analysis tool to identify potential trends in dietary exposure to chemicals in the population of interest, as an assessing tool for the effectiveness of previous risk management decisions, and to support development and/or refinement of food safety control policies and regulations in the same way as intended by the recent amendment of the Food Sanitation Act in Korea.

Known as one of the most cost-effective measures in food safety control, TDS should be placed on the top of the list for food safety control policy in Korea and, government's effort to secure the adequate resources for continuous TDS without interruption is warranted.

\section{ACKNOWLEDGEMENT}

This study was supported by a grant (13162KFDA049) from the Ministry of Food and Drug Safety in 2013 through 2015.

\section{REFERENCES}

1. Ministry of Culture Sports and Tourism. (2013) Policy Briefing. Available from: http://safe.korea.kr/newsWeb/pages/special/safesociety/index.do.

2. Ministry of Government Legislation. (2015) Food Sanitation Act. Available from: http://www.law.go.kr/lsSc.do?menuId= $0 \& \mathrm{p} 1=\&$ subMenu $=1 \&$ nw $\mathrm{Yn}=1 \&$ section $=\&$ query $=\% \mathrm{EC} \%$ 8B\%9D\%ED\%92\%88\%EC\%9C\%84\%EC\%83\%9D\%EB\%B $2 \% 95 \& \mathrm{x}=0 \& \mathrm{y}=0 \#$ liBgcolor 1 .

3. Kim, C.I. (2015) Value and Standards/Specifications of Food. Proceedings of the 2015 International Symposium and Annual Meeting of the Korean Society of Food Science and Nutrition, pp. 173.

4. World Health Organization. (2015) Total diet studies: a recipe for safer food. Available from: http://www.who.int/entity/ foodsafety/chem/TDS_recipe_2005_en.pdf.

5. Moy, G.G. and Vannoort, R.W. (2013) Total diet studiesWhat they are and why they are important in total diet studies. Springer, New York, Heidelberg, Dordrecht, London, pp. 3-10.

6. EFSA/FAO/WHO. (2011) Joint guidance of EFSA, WHO and
FAO. Towards a harmonised total diet study approach: a guidance document. EFSA J., 9, 1-66.

7. Leblanc, J.C., Guérin, T., Noël, L., Calamassi-Tran, G., Volatier, J.L. and Verger, P. (2005) Dietary exposure estimates of 18 elements from the 1st French Total Diet Study. Food Addit. Contam., 22, 624-641.

8. Lee, H.S., Cho, Y.H., Park, S.O., Kye, S.H., Kim, B.H., Hahm, T.S., Kim, M.H., Lee, J.O. and Kim, C.I. (2006) Dietary exposure of Korean population to arsenic, cadmium, lead and mercury. J. Food Compos. Anal., 19, S31-S37.

9. Food Standards Australia New Zealand. (2003) The $20^{\text {th }}$ Australian total diet survey: a total diet survey of pesticide residues and contaminants. Available from: http://www.foodstandards.gov.au/_srcfiles/Final_20th_Total_Diet_Survey.pdf.

10. Ysart, G., Miller, P., Croasdale, M., Crews, H., Robb, P., Baxter, M., de L'Argy, C. and Harrison, N. (2000) 1997 UK Total Diet Study - dietary exposures to aluminum, arsenic, cadmium, chromium, copper, lead, mercury, nickel, selenium, tin and zinc. Food Addit. Contam., 17, 775-786.

11. WHO. (1999) Report of a Joint USFDA/WHO International Workshop on Total Diet Studies in cooperation with the Pan American Health Organization. GEMS/Food, Food Safety Programme Department of Protection of The Human Environment World Health Organization. Kansas City, Missouri, USA, Available from: http://www.who.int/foodsafety/publications/chem/tds_aug1999/en/index.html. Accessed August 6, 1999.

12. WHO. (2002) GEMS/Food Total Diet Studies. Report of the $2^{\text {nd }}$ International Workshop on Total Diet Studies. Food Safety Programme Department of Protection of the Human Environment World Health Organization. Brisbane, Australia, Geneva, pp. 56-58.

13. Perelló, G., Martí-Cid, R., Llobet, J.M. and Domingo, J.L. (2008) Effects of various cooking processes on the concentrations of arsenic, cadmium, mercury, and lead in foods. $J$. Agric. Food Chem., 56, 11262-11269.

14. Ersoy, B., Yanar, Y., Küçükgülmez, A. and Çelik, M. (2006) Effects of four cooking methods on the heavy metal concentrations of sea bass fillets (Dicentrarchus labrax Linne, 1785). Food Chem., 99, 748-751.

15. IOM (Institute of Medicine) and NRC (National Research Council). (2015) A Framework for Assessing Effects of the Food System. (Nesheim, M.C., Oria, M. and Yih, P.T. Ed.) National Academies Press, Washington, DC, pp. 1-367.

16. Pennington, J.A. and Gunderson, E.L. (1987) History of the Food and Drug Administration's Total Diet Study-1961 to 1987. J. Assoc. Off. Anal. Chem., 70, 772-782.

17. Pennington, J.A., Capar, S.G., Parfitt, C.H. and Edwards, C.W. (1996) History of the Food and Drug Administration's Total Diet Study (Part II), 1987-1993. J. AOAC Int., 79, 163-170.

18. Leblanc, J.C., Guérin, T., Verger, P. and Volatier, J.L. (2004) The 1st French Total Diet Study-Mycotoxins, minerals and trace elements. INRA, Available from: http://www.tds-exposure.eu/sites/default/files/WP1/RapportEAT1EN.pdf. Accessed May 2004.

19. Leblanc, J.C., Tard, A., Volatier, J.L. and Verger, P. (2005) Estimated dietary exposure to principal food mycotoxins from the first French Total Diet Study. Food Addit. Contam., 22, 652-672. 
20. Kim, C.I., Lee, J.Y., Lee, H., Kim, D., Yon, M. and Nam, J. (2012) Korean Total Diet Study. R\&D Report to the Korea Food and Drug Administration. Available from: http:// rnd.mfds.go.kr/.

21. WHO. (2015) Meeting report on the $5^{\text {th }}$ International Workshop on Total Diet Studies. World Health Organization WPRO, Korea Ministry of Food and Drug Safety, and Korea Health Industry Development Institute. Seoul, Republic of Korea,13-14 May 2015. World Health Organization Regional Office for the Western Pacific, Manila, Philippines.

22. Lee, J.G. Kim, S.H., Kim, H.J. and Yoon, H.J. (2015) Total diet studies as a tool for ensuring food safety. Toxicol. Res., 31, 221-226.

23. World Health Organization. (2006) GEMS/Food Consumption Cluster Diets. Available from: http:/www.who.int/foodsafety/chem/gems/en/index1.html.

24. Héraud, F., Barraj, L.M. and Moy, G.G. (2013) GEMS/Food consumption cluster diets in Total Diet Studies (Moy, G.G. and Vannoort, R. W. Ed.). Springer, New York, Heidelberg, Dordrecht, London, pp. 427-434.

25. Barraj, L. and Petersen, B. (1997) A method for revising and redefining regional diets for use in estimating intake of pesticides. Presented at the Joint FAO/WHO Consultation on Food Consumption and Exposure Assessment of Chemicals, Geneva.

26. Sy, M.M., Feinberg, M., Verger, P., Barré, T., Clémençon, S. and Crépet, A. (2013) New approach for the assessment of cluster diets. Food Chem. Toxicol., 52, 180-187.

27. WHO GEMS/Food Consumption Cluster Diets. (2012) Map and List. Available from: http://www.who.int/foodsafety/ chem/Global_GEMS_CLUSTERS_2012.jpg?ua=1 and http:// www.who.int/foodsafety/chem/cluster_diets_2012.pdf?ua= $1 \& u a=1$.

28. Lee, J.Y., Lee, H., Kim, D., Yon, M., Nam, J., Kwon, S.O., Choi, A., Chang, Y.S., Shin, E.S., Baek, O.J., Suh, J., Park, S.H. and Kim, C.I. (2014) Total dietary exposure of PCBs in Koreans and related socio-demographic factors (813.9). FASEB J., 28, 813.9.

29. Becker, W. (2000) Total Diet Studies-examples from Sweden. J. Food Compos. Anal., 13, 545-549.

30. Avegliano, R.P., Maihara, V.A. and da Silava, F.F. (2015) Development of the food list for a Brazilian total diet study. Food Sci. Technol., 35, 207-212.

31. Pennington, J.A.T. (1992) The 1990 revision of the FDA Total Diet Study. J. Nutr. Educ., 24,173-178.

32. Lee, H.S., Kim, B.H., Jan, Y.A., Park, S.O., Oh, C.H., Kim, J.Y., Kim, H.Y., Chung, S.Y., Sho, Y.S., Suh, J.H., Lee, E.J. and Kim, C.I. (2005) Developing food list for risk assessment of contaminants in Korean foods. Korean J. Food Sci. Technol., 37, 660-670.

33. Charrondiere, U.R. (2013) Preparing a food list for a total diet study in Total Diet Studies (Moy, G.G. and Vannoort, R. W. Ed.). Springer, New York, Heidelberg, Dordrecht, London, pp. 53-62.

34. Koh, E., Shin, H., Yon, M., Nam, E., Lee, Y., Kim, D., Lee, J., Kim, M., Park, S.K., Choi, H. and Kim, C.I. (2011) Selection of representative foods and 'best-fit' mapping of other foods for estimation of a comprehensive exposure to food contaminants in a Korean Total Diet Study. Korean J. Food Sci. Tech- nol., 43, 773-782.

35. Darnerud, P.O., Atuma, S., Aune, M., Bjerselius, R., Glynn, A., Grawé, K.P. and Becker, W. (2006) Dietary intake estimations of organohalogen contaminants (dioxins, PCB, PBDE, and chlorinated pesticides, e.g. DDT) based on Swedish market basket data. Food Contam. Toxicol., 44, 1597-1606.

36. Becker, W., Jorhem, L., Sundström, B., Grawé, P. (2011) Contents of mineral elements in Swedish market basket diets. $J$. Food Compos. Anal., 24, 279-287.

37. WHO. (2007) GEMS/Food total diet studies: report of the 4th international workshop on Total Diet Studies, Beijing, China. WHO, pp. 1-50.

38. Church, S. (2000) The U.K. total diet study and 1995 selenium intakes. J. Food Compos. Anal., 13, 557-559.

39. Kim, C.I., Lee, J.Y., Lee, H., Kim, D., Yon, M., Nam, J. and Kwon, S. (2013) Korean Total Diet Study-PCBs. R\&D Report to the Korea Ministry of Food and Drug Safety. Available from: http://rnd.mfds.go.kr/.

40. US Department of Agriculture. (2015) What we eat in America. Available from: http://www.ars.usda.gov/Services/docs. htm?docid $=13793$.

41. Kweon, S., Kim, Y., Jang, M.J., Kim, Y., Kim, K., Choi, S., Chun, C., Khang, Y.H. and Oh, K. (2014) Data resource profile: the Korea National Health and Nutrition Examination Survey (KNHANES). Int. J. Epidemiol., 43, 69-77.

42. Yoon, H.J. (2013) Total diet studies in the Republic of Korea in Total Diet Studies (Moy, G.G. and Vannoort, R. W. Ed.). Springer, New York, Heidelberg, Dordrecht, London, pp. 327336.

43. Lee, H.S., Kim, B.H., Jang, Y.A. and Kim, C.I. (2003) Korea National Health and Nutrition Survey - Change in diet and fat intake pattern. Proceedings for the Annual Meeting of the Korean Society of Lipidology and Atherosclerosis, pp. 291311.

44. Kim, C.I., Lee, H.S., Kim, B.H., Jang, Y.A. and Suh, H.J. (2004) Change in nutritional status of the elderly population in Korea. J. Food Compos. Anal., 17, 449-457.

45. Vannoort, R.W., Abbey, J.L., Leemhuis, C. and Mooney, C. (2013) Food sampling and preparation in a total diet study in Total Diet Studies (Moy, G.G. and Vannoort, R. W. Ed.). Springer, New York, Heidelberg, Dordrecht, London, pp. 83102.

46. Egan, S.K., Bolger, P.M. and Carrington, C.D. (2007) Update of the US FDA's Total Diet Study food list and diets. J. Exposure Sci. Environ. Epidemiol., 17, 573-582.

47. FSANZ (Food Standards Australia New Zealand). (2011) The 23rd Australian Total Diet Study. Canberra: Food Standards Australia New Zealand. Available from: http://www.foodstandards.gov.au/sci enceandeducation/publications/23rdaustraliantotald5367.cfm.

48. Ruprich, J. (2003) The 2002 Total Diet Study of the Czech Republic. Available from: http://www.chpr.szu.cz/monitor/ tds $02 \mathrm{c} / \mathrm{tds} 02 \mathrm{c} . \mathrm{htm}$.

49. Kim, C.I., Lee, J.Y., Lee, H., Kim, D., Yon, M., Nam, J. and Kwon, S. (2014) Study on reducing hazardous materials in foods (HMFs)-Total exposure assessment to $23 \mathrm{HMFs}$. $1^{\text {st }}$ year interim progress report to the Korean Ministry of Food and Drug Safety.

50. Peattie, M.E., Buss, D.H., Lindsay, D.G. and Smart, G.A. 
(1983) Reorganisation of the British total diet study for monitoring food constituents from 1981. Food Chem. Toxicol., 21, 503-507.

51. Shavila, J. (2013) Total diet studies-United Kingdom's experience in total diet studies (Moy, G.G. and Vannoort, R.W. Ed.). Springer, New York, Heidelberg, Dordrecht, London, pp. 403-410.

52. Committee on Toxicity of Chemicals in Food, Consumer Products and the Environment. (2008) COT statement on the 2006 UK Total Diet Study of metals and other elements. Available from: http://cot.food.gov.uk/sites/default/files/cot/ cotstatementtds200808.pdf.

53. Leblanc, J.C., Guérin, T., Noël, L., Calamassi-Tran, G., Volatier, J.L. and Verger, P. (2005) Dietary exposure estimates of 18 elements from the 1st French Total Diet Study. Food Addit. Contam., 22, 624-641.

54. French Agency for Food, Environmental and Occupational Health and Safety (ANSES). (2011) Second French Total Diet Study (TDS 2) Report 1. Available from: http://www.tdsexposure.eu/sites/default/files/WP1/RapportEAT2EN1.pdf.

55. Egan, S.K., Tao, S.S., Pennington, J.A. and Bolger, P.M. (2002) US Food and Drug Administration's Total Diet Study: intake of nutritional and toxic elements, 1991-96. Food Addit. Contam., 19, 103-125.

56. Ministry of Agriculture and Forestry. (2011) 2009 New Zealand Total Diet Study. Available from: http://www.foodsafety.govt.nz/elibrary/industry/total-diet-study.pdf.

57. FSANZ (Food Standards Australia New Zealand). (2008) The 22nd Australian Total Diet Study. Canberra: Food Standards Australia New Zealand. Available from: http://www.foodstandards.gov.au/publications/documents/ATDS.pdf.

58. U.S. Food \& Drug Administration (FDA). (2015) Total Diet Study. Available from: http://www. fda.gov/Food/FoodSafety/ FoodContaminantsAdulteration/TotalDietStudy/deault.htm.

59. Egan, K. (2013) United States Food and Drug Administration's total diet study program in Total Diet Studies (Moy, G.G. and Vannoort, R.W. Ed.). Springer, New York, Heidelberg, Dordrecht, London, pp. 411-417.

60. Dabeka, R.W., Rawn, D.F.K., Cao, X.L. and Moisey, J. (2013) Canadian total diet study experiences in Total Diet Studies (Moy, G.G. and Vannoort, R.W. Ed.). Springer, New York, Heidelberg, Dordrecht, London, pp. 233-244.

61. Hargin, K.D. (2013) Using total diet studies to assess acrylamide exposure in Total Diet Studies (Moy, G.G. and Vannoort, R.W. Ed.). Springer, New York, Heidelberg, Dordrecht, London, pp. 489-500.

62. Tittlemier, S.A., Pepper, K. and Edwards, L. (2006) Concentrations of perfluorooctanesulfonamides in Canadian total diet study composite food samples collected between 1992 and 2004. J. Agric. Food Chem., 54, 8385-8389.

63. Choi, Y., Kim, J., Lee, H.S., Kim, C.I., Hwang, I.K., Park, H.K., Kim, T.H. and Oh, C.H. (2008) Analysis of vitamin $B_{12}$ in the Korean representative foods and dietary intake assessment for Koreans. Food Sci. Biotechnol., 17, 262-266.

64. Choi, Y., Kim, J., Lee, H.S., Kim, C.I., Hwang, I.K., Park, H.K. and Oh, C.H. (2009) Selenium content in representative Korean foods. J. Food Compos. Anal., 22, 117-122.

65. Booth, S.L., Sadowski, J.A. and Pennington, J.A.T. (1995) Phylloquinone (Vitamin K1) content of foods in the U.S. Food and Drug Administration's total diet study. J. Agric. Food Chem., 43, 1574-1 579.

66. Tittlemier, S.A., Van de Riet, J., Burns, G., Potter, R., Murphy, C., Rourke, W., Pearce, H., Cao, X.L., Dabekai, R.W. and Dufresne, G. (2007) Analysis of veterinary drug residues in fish and shrimp composites collected during the Canadian Total Diet Study, 1993 2004. Food Addit. Contam., 24, 14-20.

67. Boorman, J.L., Baines, J., Hambridge, T.L. and Abbey, J.L. (2013) Dietary exposure assessment in a total diet study in Total Diet Studies (Moy, G.G. and Vannoort, R.W. Ed.). Springer, New York, Heidelberg, Dordrecht, London, pp. 179190.

68. WHO. (2008) Dietary exposure assessment of chemicals in food. Report of a Joint FAO/WHO Consultation, Annapolis, Maryland, Geneva, pp. 1-80.

69. Dodd, K.W., Guenther, P.M., Freedman, L.S., Subar, A.F., Kipnis, V., Midthune, D., Tooze, J.A. and Krebs-Smith, S.M. (2006) Statistical methods for estimating usual intake of nutrients and foods: a review of the theory. J. Am. Diet. Assoc., 106, 1640-1650.

70. US National Cancer Institute. (2015) Usual dietary intakes: the NCI method. Available from: http://epi.grants.cancer.gov/ diet/usualintakes/method.html?\&url=/diet/usualintakes/method. html.

71. Petersen, B.J. (2013) Overview of dietary exposure in Total Diet Studies (Moy, G.G. and Vannoort, R.W. Ed.). Springer, New York, Heidelberg, Dordrecht, London, pp. 27-36.

72. Food Standards Australia New Zealand. (2009) Principles and practices of dietary exposure assessment for food regulatory purposes. Food Standards Australia New Zealand, Canberra. Available from: https://www.foodstandards.gov.au/science/ exposure/documents/Principles\%20_\%20practices\%20exposure\%20assessment $\% 202009$.pdf.

73. de Vos, R.H., van Dokkum, W., Olthoff, P.D., Quirijns, J.K., Muys, T. and van der Poll, J.M. (1984) Pesticides and other chemical residues in Dutch total diet samples (June 1976-July 1978). Food Chem. Toxicol., 22, 11-21.

74. Connolly, A., Hearty, A., Nugent, A. and Gibney, M.J. (2009) The exposure of children (5 12 years) and adults (18 65 years) to pesticide residues in their diets. Proc. Nutr. Soc., 68, E105.

75. Choi, D.W. (2009) Dietary intake and risk assessment of heavy metals (TDS). R\&D Report to the Korea Food and Drug Administration. Available from: http://rnd.mfds.go.kr/.

76. Carnovale, E., Cappelloni, M., Lombardi-Boccia, G. and Turrini, A. (2000) Total Diet Studies in Italy. J. Food Compos. Anal., 13, 551-556.

77. de Vos, R.H., van Dokkum, W., Schouten, A. and de JongBerkhoot, P. (1990) Polycyclic aromatic hydrocarbons in Dutch total diet samples (1984 1986). Food Chem. Toxicol., 28, 263-268.

78. Zhou, P.P., Zhao, Y.F., Liu, H.L., Ma, Y.J., Li, X.W., Yang, X. and $\mathrm{Wu}$, Y.N. (2013) Dietary exposure of the Chinese population to acrylamide. Biomed. Environ. Sci., 26, 421-429.

79. U.S. Food and Drug Administration. (2007) PCDD/PCDF exposure estimates from Non-TDS foods Analyzed in 20012003. Available from: http://www.fda.gov/Food/FoodborneIllnessContaminants/ChemicalContaminants/ucm077478.htm.

80. Koh, E., Shin, H., Yon, M., Nam, J.W., Lee, Y., Kim, D., Lee, 
J., Kim, M., Park, S.K., Choi, H. and Kim. C.I. (2012) Measures for a closer-to-real estimate of dietary exposure to total mercury and lead in total diet study for Koreans. Nutr. Res. Pract., 6, 436-443.

81. Ministry of Health and Welfare, Korea Centers for Disease Control and Prevention. (2008) 2007 National health statistics - The fourth Korea national health \& nutrition examination survey (KNHANES IV). Korea Centers for Disease Control and Prevention, Cheongwon.

82. Boorman, J.L., Baines, J., Hambridge, T.L. and Abbey, J.L. (2013) Food mapping in a total diet study in Total Diet Studies (Moy, G.G. and Vannoort, R. W. Ed.). Springer, New York, Heidelberg, Dordrecht, London, pp. 435-444.

83. Kim, C.I., Koh, E., Shin, H., Yon, M., Nam, E., Lee, Y., Kim, D. and Lee, J.Y. (2011) Planning of Total Diet Study for hazardous materials. R\&D Report to the Korea Food and Drug
Administration. Available from: http://rnd.mfds.go.kr/.

84. Kim, C.I., Lee, J.Y., Lee, H., Kim, D., Yon, M., Nam, J. and Kwon, S. (2015) Study on reducing hazardous materials in foods (HMFs)-Total exposure assessment to $23 \mathrm{HMFs}$. $2^{\text {nd }}$ year interim progress report to the Korean Ministry of Food and Drug Safety.

85. Lee, J.Y., Kwon, S., Lee, H., Kim, D., Yon, M., Nam, J., Choi, A., Kim, C.I., Lee, J.G. and Yoon, H.J. (2015) Study on reducing hazardous materials in foods (HMFs) - design and methods of the Korean Total Diet Study. Proceedings of the International Conference on Diet and Activity Methods 2015, pp. 152.

86. Ministry of Government Administration and Home Affairs. (2013) Statistics on resident registry. Available from: http:// rcps.egov.go.kr:8081/jsp/stat/ppl_stat_jf.jsp. 